\title{
Is There a Role for Tranexamic Acid in Upper GI Bleeding? A Systematic Review and Meta-Analysis
}

\author{
Eoghan Burke $\left(\mathbb{D},{ }^{1}\right.$ Patricia Harkins, ${ }^{2}$ and Ibrahim Ahmed ${ }^{3}$ \\ ${ }^{1}$ Royal College of Surgeons, Dublin, Ireland \\ ${ }^{2}$ St James's Hospital, Dublin, Ireland \\ ${ }^{3}$ Our Lady of Lourdes Hospital, Drogheda, Ireland \\ Correspondence should be addressed to Eoghan Burke; eoghanburke@rcsi.ie
}

Received 27 August 2020; Revised 3 January 2021; Accepted 15 January 2021; Published 29 January 2021

Academic Editor: Miltiadis I. Matsagkas

Copyright (c 2021 Eoghan Burke et al. This is an open access article distributed under the Creative Commons Attribution License, which permits unrestricted use, distribution, and reproduction in any medium, provided the original work is properly cited.

Introduction. Upper gastrointestinal (GI) bleeding is associated with increased morbidity and mortality. Tranexamic acid (TXA) is an antifibrinolytic agent which is licensed in the management of haemorrhage associated with trauma. It has been suggested that tranexamic acid may be able to play a role in upper GI bleeding. However, there is currently no recommendation to support this. Aim. The aim of this study was to synthesise available evidence of the effect of TXA on upper GI bleeding. Methods and Materials. A systematic review was conducted. PubMed, EMBASE, and Cochrane Central Register of Controlled Trials (CENTRAL) were searched for relevant studies. A random effects meta-analysis was performed to determine the risk ratio of primary and secondary outcomes pertaining to the use of TXA in upper GI bleeding. Results. A total of 8 studies were included in this systematic review. The total number of patients in all studies was 12994 including 4550 females (35\%) and 8444 males (65\%). The mean age of participants in 6 of the studies was 59.3; however the mean age for either intervention or placebo group was not reported in two of the studies. All studies reported on the effect of TXA on mortality, and the risk ratio was 0.95; however, with the $95 \%$ CI ranging from 0.80 to 1.13 , this was not statistically significant. 6 of the studies reported on rebleeding rate, the risk ratio was 0.64 , and with a $95 \%$ CI ranging from 0.47 to 0.86 , this was statistically significant. 3 of the studies reported on the risk of adverse thromboembolic events, and the risk ratio was 0.93 ; however, the $95 \%$ CI extended from 0.62 to 1.39 and so was not statistically significant. 7 of the studies reported on the need for surgery, and the risk ratio was 0.59 and was statistically significant with a $95 \%$ CI ranging from 0.38 to 0.94 . Conclusion. In conclusion, the use of TXA in upper GI bleeding appears to have a beneficial effect in terms of decreasing the risk of re-bleeding and decreasing the need for surgery. However, we could not find a statistically significant effect on need for blood transfusions, risk of thromboembolic events, or effect on mortality. Future randomised controlled trials may elucidate these outcomes.

\section{Introduction}

Upper gastrointestinal (GI) bleeding is defined as bleeding from the GI tract proximal to the Ligament of Treitz or the duodenojejunal flexure which delineates the transition from the duodenal to the jejunal portion of the small bowel. Acute severe GI bleeding is a common cause of death across the world [1], with upper GI bleeding being more common than lower GI bleeding. Not only is upper GI bleeding more common than lower GI bleeding, it also portends a higher mortality rate approaching $10 \%$ compared to $3 \%$ for lower GI bleeding [2]. GI bleeding is also associated with increased healthcare cost associated with interventions, need for surgery, prolonged hospital stays, and risk of rebleeding [3].

The majority of upper GI bleeding cases globally are associated with peptic ulcer disease (PUD); however, this incidence is decreasing globally secondary to the widespread eradication of Helicobacter pylori (H. pylori) with triple therapy. Other commonly encountered aetiologies include oesophagitis (infectious, inflammatory, eosinophilic, reflux), gastritis (with or without $H$. pylori as an aetiological factor), vascular abnormalities (Dieulafoy lesions, Gastric Antral Vascular Ectasia), and variceal bleeding [4]. 
Given the increased risk of morbidity and mortality alongside increased healthcare costs associated with managing patients presenting with acute upper GI bleeding, much research has been applied into this area in an effort to improve outcomes. Since the advent of endoscopy, and therapeutic endoscopy in particular, the mortality rates associated with acute upper GI bleeding have fallen [5]. However, there are recognized issues with access to advanced endoscopy in many resource deprived areas around the world which results in higher rates of morbidity and mortality for patients presenting with acute upper GI bleeding [6]. It is in this setting that there appears to be an increased interest in the role of tranexamic acid (TXA) as an adjunct in the management of these patients.

TXA is an antifibrinolytic agent which is licensed in the management of haemorrhage associated with trauma and major obstetric haemorrhage [7]. TXA acts by inhibiting the breakdown of fibrin by plasmin and so maintains the primary platelet plug which subsequently allows for maintenance of a thrombus [8]. It can be given via intravenous infusion or by mouth. Its use and benefit in trauma have been well studied, namely, in the CRASH 2 trial [9].

It has long been thought intuitively that TXA may be able to play a role in other instances of haemorrhage such as upper GI bleeding. However, there is currently no recommendation to support this.

The aim of this study was to synthesise available evidence of the effect of TXA on upper GI bleeding.

\section{Materials and Methods}

2.1. Study Aim and Objectives. The aim of this study was to synthesise available evidence of the effect of tranexamic acid on upper GI bleeding.

The primary objectives of the study are as follows:

(i) To assess the effect of TXA versus placebo on the rate of mortality, rebleeding, and adverse events in patients with upper GI bleeding. The adverse events selected, based on literature review, focus on thrombotic adverse events, given the mechanism of action of TXA.

The secondary objectives of the study are as follows:

(i) To assess the effect of TXA versus placebo on the need for surgery and blood product transfusion in patients presenting with upper GI bleeding.

The PICO model was used to devise the search criteria, defined in detail in Table 1.

\subsection{Methods}

2.2.1. Study Design. This study was a systematic review and meta-analysis of published randomised controlled trials. Reporting of this systematic review is in accordance with the Preferred Reporting Items for Systematic Reviews and MetaAnalyses (PRISMA) statement.
2.2.2. Eligibility Criteria. Inclusion criteria were as follows:

(i) Randomised controlled clinical trials

(ii) Adult patients (definition depending on jurisdiction $>16$ or $>18$ )

(iii) Suspected or endoscopically verified upper GI bleeding

(iv) Intervention: tranexamic acid, either intravenous or oral administration

(v) Comparator: placebo

(vi) Outcome: must have primary outcomes reported and ideally secondary outcomes

Exclusion criteria were as follows:

Paediatric participants.

2.3. Search Strategy. A detailed search strategy was developed following literature review. Key words and $\mathrm{MeSH}$ terms relating to tranexamic acid and upper GI bleeding were used to develop the search string: ((tranexamic acid) OR (TXA)) AND ((upper gastrointestinal bleeding) OR (upper gastrointestinal haemorrhage) OR UGIB). This search string was applied to the bibliographic databases on $22^{\text {nd }}$ June 2019: PubMed, EMBASE, and the Cochrane Central Register of Controlled Trials (CENTRAL). This combination of bibliographic databases was chosen based on the findings by Bramer et al. [10] on the optimum database combinations to be searched for a systematic review. We elected to use Google scholar to conduct a citation search during the study selection process, described below. This ensured that we were unlikely to miss relevant studies while limiting the amount of initial results to be screened. A variant of the above search string was applied to the relevant clinical trial registries (Clinicaltrials.gov, Japanese Medical Association Clinical Trials Registry and the EU clinical trials register) to identify potential grey literature. All databases were searched from inception.

2.4. Study Selection. After duplicates were removed, all of the identified studies' titles and abstracts were independently screened by two of the authors (E. Burke and P. Harkins). Abstracts meeting the previously described inclusion criteria were selected. If there was any conflict about a study's inclusion, this was resolved by a third author (I. Ahmed). The resulting studies were then reviewed in full and eligibility for inclusion in qualitative and quantitative analysis determined. Any conflict pertaining to a study's eligibility was resolved with consensus. During full article review, hand searching of references to identify any studies not identified in the original search was conducted. Similarly, a citation search using Google Scholar on all eligible articles was completed again to ensure no further studies were omitted.

2.5. Data Extraction. Two of the authors (E. Burke and P. Harkins) independently extracted data from the selected studies using a predetermined data extraction form. Data 
TABLE 1: PICO model used to define search criteria for search strategy to be used in the relevant bibliographic databases.

\begin{tabular}{lccc}
\hline$P$ & $I$ & $C$ & $O$ \\
\hline $\begin{array}{l}\text { Population } \\
\text { Adult patients presenting with upper } \\
\text { GI bleeding }\end{array}$ & Intervention & Comparison & Outcome \\
& $\begin{array}{c}\text { Tranexamic acid given intravenously or } \\
\text { by mouth }\end{array}$ & Placebo & $\begin{array}{c}\text { Primary and secondary outcomes as } \\
\text { outlined above }\end{array}$ \\
\hline
\end{tabular}

extracted included method of study, participant characteristics, intervention used, and outcomes including mortality, rebleeding, adverse thrombotic events, need for surgery, and transfusion requirement.

2.6. Risk of Bias Assessment. The quality and risk of bias in each study were assessed independently by two authors (E. Burke and P. Harkins) using the Cochrane Collaboration Risk of Bias tool [11]. This tool assesses each study's susceptibility to selection bias, performance bias, detection bias, attrition bias, and reporting bias. The susceptibility was rated as either low risk, high risk, or unclear risk. The results were depicted graphically using RevMan software.

2.7. Summary Measures and Synthesis of Results. We conducted a qualitative assessment (systematic review) of all eligible studies. Eligible studies reporting the outcomes were synthesised quantitatively using meta-analysis.

Studies comparing TXA versus placebo were pooled together. The relative risk for each outcome (either primary or secondary) and number of participants in each group were then extracted to facilitate a pair-wise meta-analysis to determine the risk ratio for each outcome when comparing the effect of TXA versus placebo. Risk ratios were used as the outcomes were dichotomous measures.

If at least three studies comparing TXA versus control were available, these were then compared for a given outcome (either primary or secondary). Care was taken to avoid making a unit of analysis error in the case of studies with multiple intervention or control arms.

Statistical heterogeneity amongst the studies was calculated using $I^{2}$. A $P$-value of less than 0.05 was considered significant where appropriate.

The statistical analysis of the data was conducted using the Cochrane Collaboration guidelines including the use of RevMan $5.3^{\circledR}$ statistical software.

\section{Results}

3.1. Study Selection. The number of articles found via searching the bibliographic databases PubMed, EMBASE, and Cochrane Central Register of Controlled Trials was 322. A further 16 articles were found by hand-searching of references or via citation searching on Google Scholar. Following removal of duplicates, the number of original articles to screen was 298. Screening of the title and abstract of these articles was performed independently by E. Burke and P. Harkins. Articles meeting criteria for further evaluation of full text numbered 9. Of these 9 studies, 1 was excluded as it did not use the defined intervention. Thus, 8 studies were included in the final review for narrative synthesis; all were deemed suitable to include in metaanalysis (Figure 1).

It should also be noted that the recent HALT-IT trial was included in this study even though it assessed the effects of TXA on GI bleeding in general but not isolated to upper GI sources. The reasoning behind this was the fact that the study reported that over $89 \%$ of those included in the study were deemed to have an upper GI bleed and thus it should be translatable to our study [12]. Also, this study is the largest and most recent study of its kind assessing this question and so it was deemed appropriate to include it with the above proviso acknowledged.

3.2. Study Characteristics. The characteristics of the studies included are detailed in Table 2. A total of 8 studies were included in this systematic review [12-19]. The number of patients included in the studies ranged from a low of 47 to a high of 12009 . The total number of patients in all 8 studies was 12994 including 4550 females (35\%) and 8444 males (65\%). The mean age of participants in 6 of the studies was 59.3; however, the mean age for either intervention or placebo group was not reported in two of the studies, namely, Cormack 1973 and Biggs 1976.

All of the included studies used the same intervention, namely, TXA; however, there was significant heterogeneity both in terms of dose, method of administration, and duration of treatment (Table 2). All included studies used placebo as the control arm.

In terms of the reporting of both primary and secondary outcomes, all studies reported on mortality, 6 studies reported on rebleeding rates, only 3 reported on adverse thromboembolic events, 7 studies reported on the need for surgery, and 6 studies reported on transfusion requirement.

3.3. Risk of Bias Assessment. Study quality in terms of risk of bias was assessed independently by E. Burke and P. Harkins using the Cochrane Collaboration Risk of Bias tool. The results are outlined in Figures 2 and 3.

3.4. Synthesis of Results for Meta-Analysis. A random effects meta-analysis was then performed to determine the risk ratio of a given outcome comparing the TXA group to the placebo group.

All 8 studies reported on mortality as an outcome. Results were graphed in a forest plot (Figure 4). This revealed a risk ratio of 0.95 with a $95 \%$ confidence interval (CI) of between 0.80 and 1.13. The $Z$ statistic for the overall effect size was 0.58 but was not statistically significant with a 


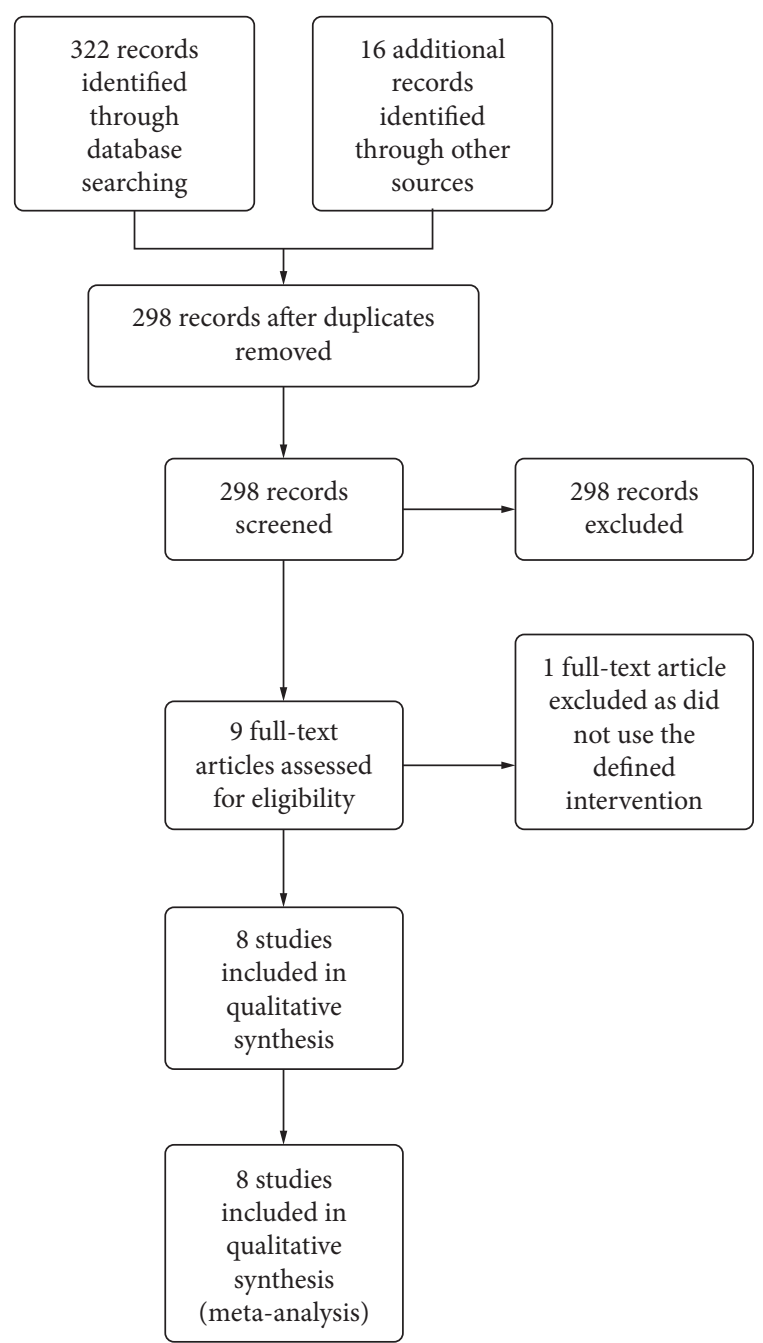

Figure 1: Prisma flowchart, preferred reporting items for systematic reviews and meta-analyses. This depicts the selection of studies for meta-analysis.

$P$-value of 0.56 . The included studies were homogenous as evidenced by the $I^{2}$ value of $0 \%$.

3.4.1. Rebleeding Rate. 6 of the studies reported on rebleeding rate as an outcome. Results were graphed in a forest plot (Figure 5). This revealed a risk ratio of 0.64 with a 95\% CI of between 0.47 and 0.86 . The $Z$ statistic for the overall effect size was 2.93 and was statistically significant with a $P$-value of 0.003 . The included studies were homogenous as evidenced by the $I^{2}$ value of $0 \%$.

3.4.2. Adverse Thromboembolic Events. 3 of the studies reported on adverse thromboembolic events (namely, myocardial infarction, cerebrovascular accidents, and pulmonary emboli). Results were graphed in a forest plot (Figure 6). This revealed a risk ratio of 0.93 with a $95 \% \mathrm{CI}$ of between 0.62 and 1.39. The $Z$ statistic for the overall effect size was 0.34 but was not statistically significant with a $P$ value of 0.73 . The included studies were homogenous as evidenced by the $I^{2}$ value of $0 \%$.

3.4.3. Need for Surgery. 7 of the studies reported on the subsequent need for surgery in these patients enrolled in the study. Results were graphed in a forest plot (Figure 7). This revealed a risk ratio of 0.59 with a $95 \%$ CI of between 0.38 and 0.94 . The $Z$ statistic for the overall effect size was 2.21 and was statistically significant with a $P$-value of 0.03 . The included studies were heterogenous as evidenced by the $I^{2}$ value of $56 \%$.

3.4.4. Need for Transfusion. 6 of the studies reported on transfusion requirement. Results were graphed in a forest plot (Figure 8). This revealed a risk ratio of 0.99 with a $95 \%$ CI of between 0.97 and 1.02 . The $Z$ statistic for the overall effect size was 0.60 and was not statistically significant with a $P$-value of 0.55 . The included studies were homogenous as evidenced by the $I^{2}$ value of $0 \%$.

\section{Discussion}

TXA was discovered in Japan in 1962 by two Japanese researchers, Shosuke and Utako [20]. Their research had focused on the inhibition of enzymatic breakdown of fibrin. The chemical they initially discovered, which displayed this ability, was AMCHA later referred to as tranexamic acid (TXA) [21]. TXA is a synthetic derivative of the amino acid lysine that inhibits fibrinolysis by blocking the interaction of plasminogen with the lysine residues of fibrin [22].

Initially, TXA was marketed as an agent which could be used in the management of mild bleeding associated with dental procedures. However in 1966, again in Japan, Kobayashi and Sugiura published a paper in which they examined the role of tranexamic acid in obstetric haemorrhage [23]. Their results were impressive indicating a significant reduction in blood loss, need for transfusion, and risk of mortality. Following this seminal study, multiple studies were then conducted assessing the role of this antifibrinolytic agent in multiple different fields. Most contemporaneously, the CRASH 2 trial examined the role of TXA in trauma [24].

To date, the role of TXA in upper GI bleeding is not routine practice. Our extensive literature search identified 8 relevant randomised controlled trials which examined the effect of TXA on multiple outcomes pertaining to upper GI bleeding. Our narrative review of these studies revealed significant heterogeneity amongst the studies in relation to mode of administration, dose of TXA, and duration of treatment. This systematic review and meta-analysis is the first to incorporate the data from the large HALT-IT trial. However unfortunately this trial did not focus specifically on upper GI bleeding nor did it assess some of the primary and secondary outcomes of interest. 
TABLE 2: Summary of studies included in systematic review.

\begin{tabular}{|c|c|}
\hline Study ID & Characteristics \\
\hline \multirow[t]{27}{*}{ HALT-IT 2020} & Methods: \\
\hline & Randomised controlled trial \\
\hline & Participants: \\
\hline & 12009 patients randomly assigned \\
\hline & Inclusion criteria: \\
\hline & GI bleed (upper or lower, however $89 \%$ were classified as upper GI bleeds) \\
\hline & Mean age TXA group: 58 \\
\hline & Mean age placebo group: 58 \\
\hline & 7743 males \\
\hline & 4266 females \\
\hline & Interventions: \\
\hline & TXA $1 \mathrm{~g}$ IV stat then $3 \mathrm{~g}$ infused over 24 hours \\
\hline & Outcomes: \\
\hline & Mortality: \\
\hline & TXA group 222/5994 \\
\hline & Placebo group 226/6015 \\
\hline & Rebleeding: \\
\hline & Not reported \\
\hline & Adverse events MI, CVA, PE: \\
\hline & TXA group $42 / 5994$ \\
\hline & Placebo group 46/6015 \\
\hline & Need for surgery: \\
\hline & TXA group 146/5994 \\
\hline & Placebo group $158 / 6015$ \\
\hline & Transfusion required: \\
\hline & TXA group 4076/5994 \\
\hline & Placebo group $4129 / 6015$ \\
\hline \multirow[t]{27}{*}{ Bagnenko 2011} & Methods: \\
\hline & Randomised controlled trial \\
\hline & Participants: \\
\hline & 47 patients randomly assigned \\
\hline & Inclusion criteria: \\
\hline & Suspected upper GI bleed \\
\hline & Mean age TXA group: 62 \\
\hline & Mean age placebo group: 64 \\
\hline & 29 males \\
\hline & 18 females \\
\hline & Interventions: \\
\hline & TXA $10 \mathrm{mg}$ IV/PO TDS for 3 days versus placebo \\
\hline & Outcomes: \\
\hline & Mortality: \\
\hline & TXA group $1 / 22$ \\
\hline & Placebo group $3 / 25$ \\
\hline & Rebleeding: \\
\hline & TXA group 2/22 \\
\hline & Placebo group: $5 / 25$ \\
\hline & Adverse events: \\
\hline & Not reported \\
\hline & Need for surgery: \\
\hline & TXA $1 / 22$ \\
\hline & Placebo $3 / 25$ \\
\hline & Transfusion required: \\
\hline & TXA $14 / 22$ \\
\hline & Placebo $13 / 25$ \\
\hline
\end{tabular}


TABle 2: Continued.

\begin{tabular}{|c|c|}
\hline Study ID & Characteristics \\
\hline Hawkey 2001 & $\begin{array}{c}\text { Methods: } \\
\text { Randomised controlled trial } \\
\text { Participants: } \\
206 \text { patients randomly assigned. } \\
\text { Inclusion criteria: } \\
\text { Suspected upper GI bleed } \\
\text { Mean age TXA group: } 58 \\
\text { Mean age placebo group: } 58 \\
126 \text { males } \\
80 \text { females } \\
\text { Interventions: } \\
\text { Outcomes: } \\
\text { Mortality: } \\
\text { TXA group } 4 / 103 \\
\text { Placebo group } 5 / 103 \\
\text { Rebleeding: } \\
\text { TXA group } 9 / 103 \\
\text { Placebo group: } 10 / 103 \\
\text { Adverse events: } \\
\text { g PO bolus then } 1 \text { g QDS for } 4 \text { days } \\
\text { Need for surgery: } \\
\text { TXA 5/103 } \\
\text { Placebo } 6 / 103 \\
\text { Transfusion required: } \\
\text { TXA 58/103 } \\
\text { Placebo } 60 / 103\end{array}$ \\
\hline Holstein 1987 & $\begin{array}{c}\text { Methods: } \\
\text { Randomised controlled trial } \\
\text { Participants: } \\
128 \text { patients randomly assigned } \\
\text { Inclusion criteria: } \\
\text { Suspected upper GI bleed } \\
\text { Mean age TXA group: } 62 \\
\text { Mean age placebo group: } 65 \\
90 \text { males } \\
38 \text { females } \\
\text { Interventions: } \\
\text { Outcomes: } \\
\text { Mortality: } \\
\text { TXA group 2/128 } \\
\text { Placebo group 4/128 } \\
\text { Rebleeding: } \\
\text { TXA group 10/128 } \\
\text { Placebo group } 19 / 128 \\
\text { Adverse events MI, CVA, PE: } \\
\text { TXA group 0/128 } 5 \text { days } \\
\text { Placebo group 2/128 } \\
\text { Need for surgery: } \\
\text { TXA group 3/128 } \\
\text { Placebo group 15/128 } \\
\text { Transfusion required: } \\
\text { TXA group 47/128 } \\
\text { Placebo group 54/128 }\end{array}$ \\
\hline
\end{tabular}


TABle 2: Continued.

\begin{tabular}{|c|c|}
\hline Study ID & Characteristics \\
\hline Bergqvist 1980 & $\begin{array}{c}\text { Methods: } \\
\text { Randomised controlled trial } \\
\text { Participants: } \\
50 \text { patients randomly assigned } \\
\text { Inclusion criteria: } \\
\text { Suspected upper GI bleed } \\
\text { Mean age TXA group: } 61 \\
\text { Mean age placebo group: } 58 \\
40 \text { males } \\
10 \text { females } \\
\text { Interventions: } \\
\text { Outcomes: } \\
\text { Mortality: } \\
\text { TXA group } 3 / 25 \\
\text { Placebo group 5/25 } \\
\text { Rebleeding: } \\
\text { Not reported } \\
\text { g PO hourly for two days } \\
\text { Not reported } \\
\text { Adverse events MI, CVA, PE: } \\
\text { Need for surgery: } \\
\text { TXA group } 7 / 25 \\
\text { Placebo group } 7 / 25 \\
\text { Transfusion required: } \\
\text { Not reported }\end{array}$ \\
\hline Engquist 1979 & $\begin{array}{c}\text { Methods: } \\
\text { Randomised controlled trial } \\
\text { Participants: } \\
204 \text { patients randomly assigned } \\
\text { Inclusion criteria: } \\
\text { Suspected upper GI bleed } \\
\text { Mean age TXA group: } 59 \\
\text { Mean age placebo group: } 56 \\
159 \text { males } \\
45 \text { females } \\
\text { Interventions: } \\
\text { Outcomes: } \\
\text { Mortality: } \\
\text { TXA group 11/102 } \\
\text { g IV 4 hourly for } 1 \text { day then } 1.5 \text { POS for } 6 \text { days } \\
\text { Placebo group } 12 / 102 \\
\text { Rebleeding: } \\
\text { TXA group 23/102 } \\
\text { Placebo group 29/102 } \\
\text { Adverse events MI, CVA, PE: } \\
\text { TXA group 4/102 } \\
\text { Placebo group 2/102 } \\
\text { Need for surgery: } \\
\text { TXA group 10/102 } \\
\text { Placebo group 18/102 } \\
\text { Transfusion required: } \\
\text { Not reported } \\
\text { Methods: } \\
\text { Randomised controlled trial } \\
\text { Participants: } \\
\text { Inclusion criteria: } \\
\text { 200 patients randomly assigned } \\
\text { Suspected upper GI bleed } \\
\text { Mean age TXA group: not reported } \\
\text { age placebo group: not reported } \\
\text { 156 males } \\
44 \text { females }\end{array}$ \\
\hline
\end{tabular}


TABLE 2: Continued.

\begin{tabular}{|c|c|}
\hline Study ID & Characteristics \\
\hline & $\begin{array}{l}\text { Interventions: } \\
\text { TXA } 1 \mathrm{~g} \text { IV stat then } 1 \mathrm{~g} \text { PO QDS on day } 1 \text {, } \\
\text { Then } 1 \mathrm{~g} \text { QDS for } 4 \text { days } \\
\text { Outcomes: } \\
\text { Mortality: } \\
\text { TXA group 2/103 } \\
\text { Placebo group } 4 / 97 \\
\text { Rebleeding: } \\
\text { TXA group 7/103 } \\
\text { Placebo group } 21 / 97 \\
\text { Adverse events MI, CVA, PE: } \\
\text { Not reported } \\
\text { Need for surgery: } \\
\text { TXA group 7/103 } \\
\text { Placebo group } 21 / 97 \\
\text { Transfusion required: } \\
\text { TXA group 77/103 } \\
\text { Placebo group 71/97 }\end{array}$ \\
\hline Cormack 1973 & $\begin{array}{c}\text { Methods: } \\
\text { Randomised controlled trial } \\
\text { Participants: } \\
150 \text { patients randomly assigned } \\
\text { Inclusion criteria: } \\
\text { Suspected upper GI bleed } \\
\text { Mean age TXA group: not reported } \\
\text { Mean age placebo group: not reported } \\
101 \text { males } \\
49 \text { females } \\
\text { Interventions: } \\
\text { TXA 1.5 QDS for } 7 \text { days } \\
\text { Outcomes: } \\
\text { Mortality: } \\
\text { TXA group 3/76 } \\
\text { Placebo group 3/74 } \\
\text { Rebleeding: } \\
\text { TXA group 8/76 } \\
\text { Placebo group } 11 / 74 \\
\text { Adverse events MI, CVA, PE: } \\
\text { Not reported } \\
\text { Need for surgery: } \\
\text { Not reported } \\
\text { Transfusion required: } \\
\text { TXA group 68/76 } \\
\text { Placebo group 63/74 }\end{array}$ \\
\hline
\end{tabular}

Our study has found that the use of TXA in upper GI bleeding decreases the rebleeding rate with a risk ratio of 0.64 favouring the TXA group and with a 95\% CI ranging from 0.47 to 0.86 ; this was statistically significant. We can also say that the use of TXA in this setting decreases the need for surgery in this cohort of patients presenting with upper GI bleeding with a risk ratio of 0.59 favouring the TXA group and a $95 \%$ CI ranging from 0.38 to 0.94 confirming statistical significance.

However, our results in relation to the remaining primary and secondary outcomes were less clear. All 8 studies reported on the effect of TXA on mortality; however, as the
95\% CI ranged from 0.80 to 1.13 , its effect is not statistically significant. Similarly, in the 3 studies which reported on the risk of adverse thromboembolic events the 95\% CI extended from 0.62 to 1.39 and so, again, was not statistically significant. Furthermore, when we consider the 6 studies that assessed the effect of TXA on the need for transfusion in upper GI bleeding, the risk ratio of 0.99 had a $95 \%$ CI ranging from 0.97 to 1.02 and so was not statistically significant.

Currently, there are a further two studies assessing the role of TXA in upper GI bleeding. The efficacy and tolerance of early administration of TXA in patients with cirrhosis 


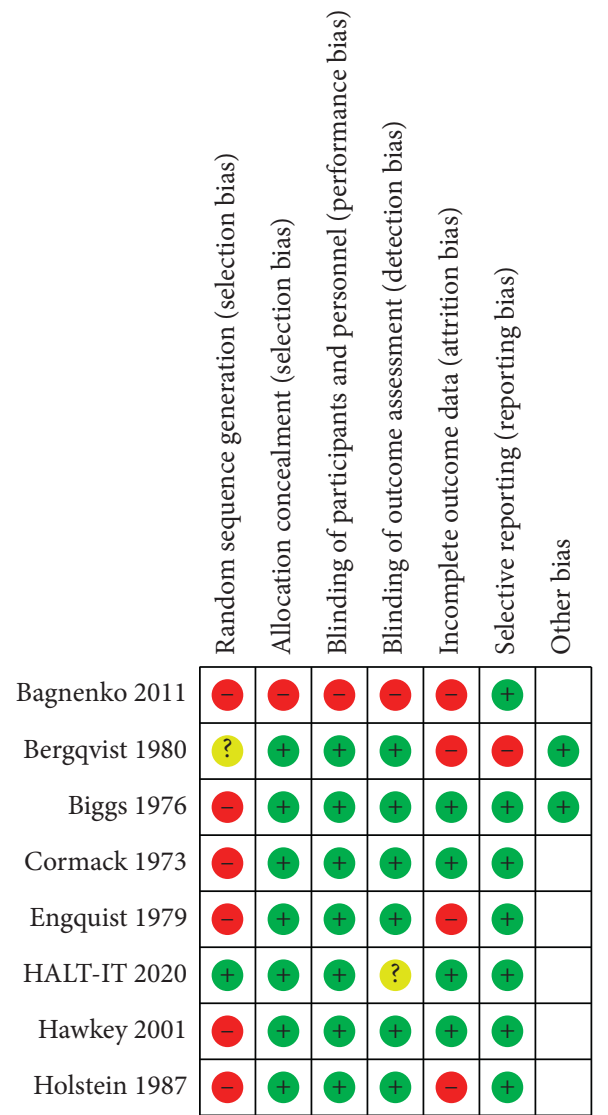

FIGURE 2: Risk of bias summary: review authors' judgements about each risk of bias item for each included study.

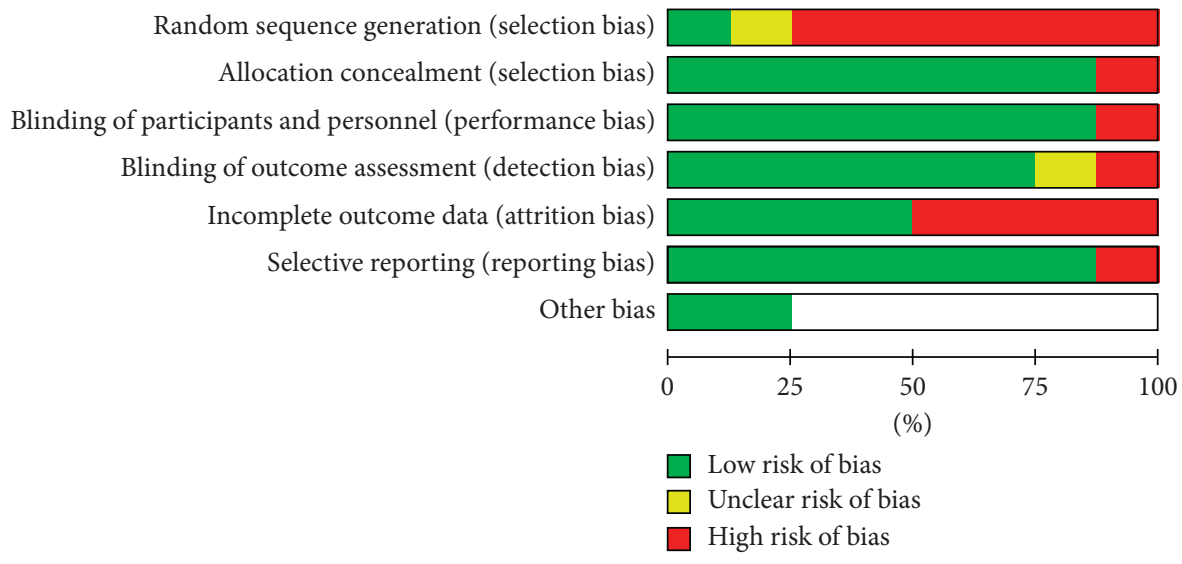

FIGURE 3: Risk of bias graph: review authors' judgements about each risk of bias item presented as percentages across all included studies.

presenting with acute upper gastrointestinal bleeding study (the EXARHOSE study) is currently enrolling [25] whilst the Tranexamic Acid for Upper Gastrointestinal Bleeding (TAUGIB) study in South Korea has recruited 414 patients to date [26]. The combination of results from both the TAUGIB and EXARHOSE studies will indeed by informative in future use of TXA in upper GI bleeding. These studies will hopefully shed more light on the effect of TXA on mortality, risk of adverse thromboembolic events, and need for transfusion.

The limitations of this present systematic review and metaanalysis include the heterogeneity of the included studies. The heterogeneity pertains to sample size, dose of TXA used, and duration of treatment. There was also a degree of heterogeneity amongst the included studies in relation to reporting of the primary and secondary outcomes of this review. 


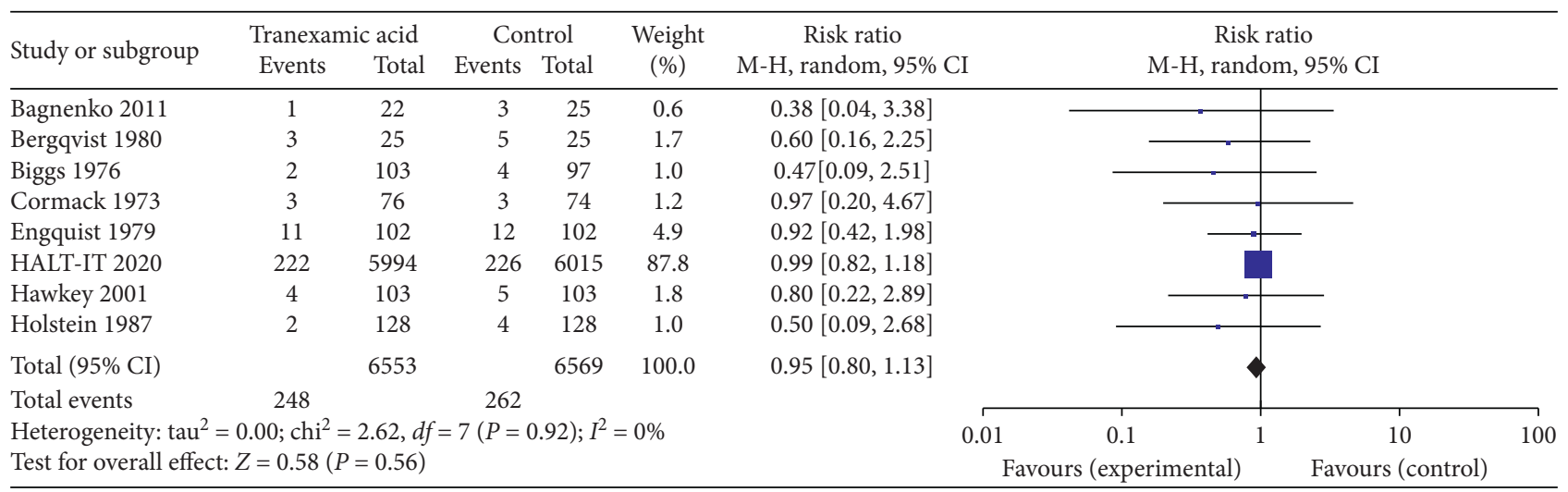

FIGURE 4: Forest plot of effect of tranexamic acid versus placebo on mortality.

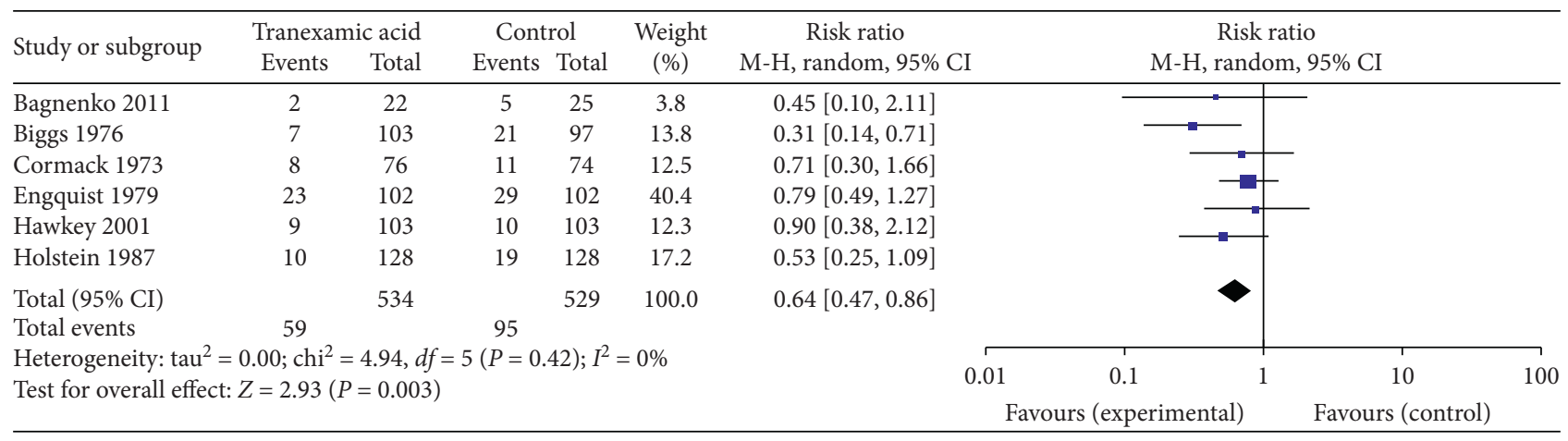

Figure 5: Forest plot of effect of tranexamic acid versus placebo on rebleeding rate.

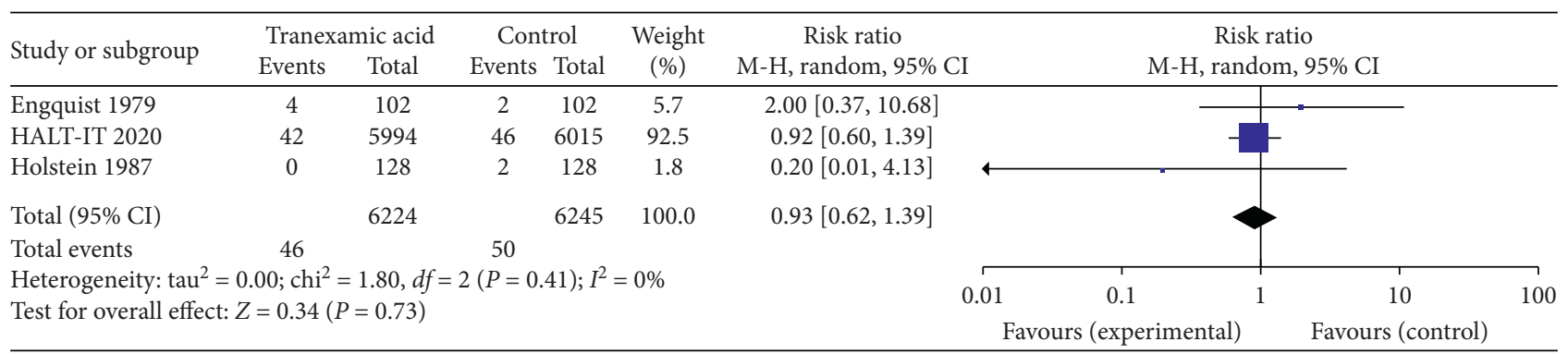

Figure 6: Forest plot of effect of tranexamic acid versus placebo on risk of thrombotic events, namely, myocardial infarction, cerebrovascular accident, and pulmonary embolism.

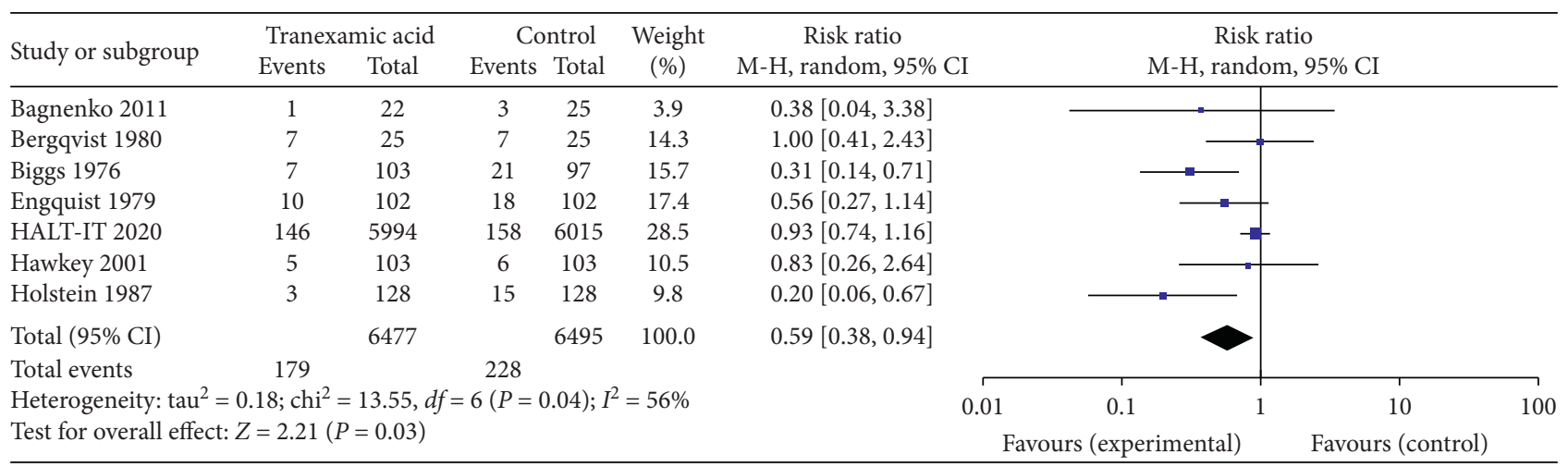

FIgURE 7: Forest plot of effect of tranexamic acid versus placebo on need for surgery. 


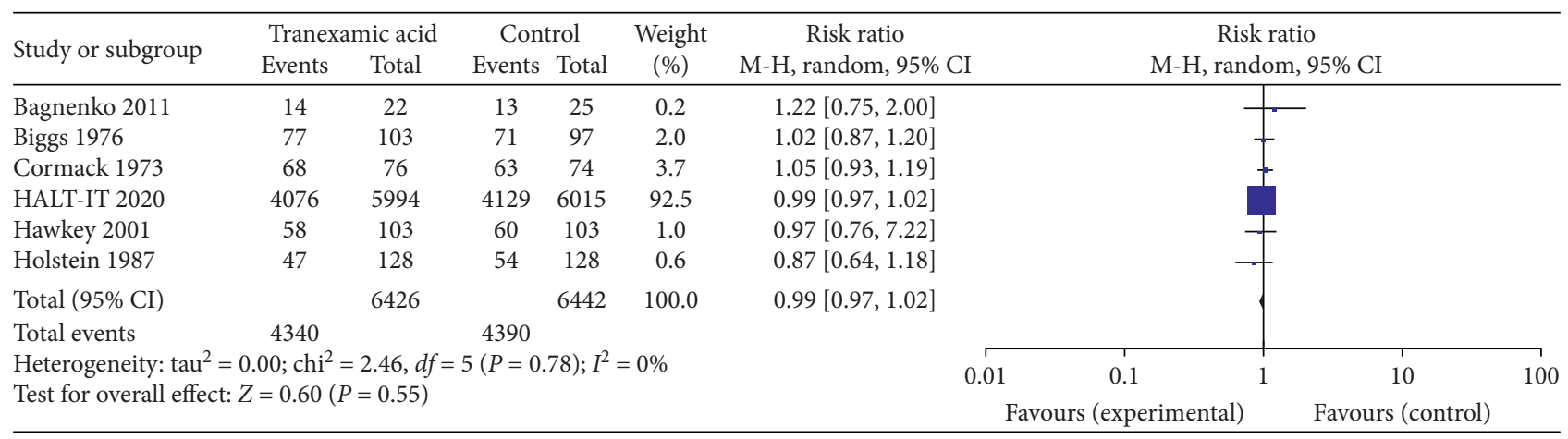

FIGURE 8: Forest plot of effect of tranexamic acid versus placebo on need for transfusion.

\section{Conclusions}

TXA use in upper GI bleeding does appear to decrease the risk of rebleeding and decrease the need for surgical intervention. However, its effect on mortality, adverse events, and transfusion requirements remains unclear. Future randomised controlled trials may elucidate these outcomes.

\section{Data Availability}

The data are freely available via search strategy as this is a systematic review and meta-analysis of published articles.

\section{Conflicts of Interest}

The authors declare that they have no conflicts of interest.

\section{References}

[1] M. E. Van Leerdam, "Epidemiology of acute upper gastrointestinal bleeding," Best Practice \& Research Clinical Gastroenterology, vol. 22, no. 2, pp. 209-224, 2008.

[2] S. A. Hearnshaw, R. F. A. Logan, D. Lowe, S. P. L. Travis, M. F. Murphy, and K. R. Palmer, "Acute upper gastrointestinal bleeding in the UK: patient characteristics, diagnoses and outcomes in the 2007 UK audit," Gut, vol. 60, no. 10, pp. 1327-1335, 2011.

[3] S. H. Kim, J. M. Yun, C. B. Chang, H. Piao, S. J. Yu, and D. W. Shin, "Prevalence of upper gastrointestinal bleeding risk factors among the general population and osteoarthritis patients," World Journal of Gastroenterology, vol. 22, no. 48, p. 10643, 2016.

[4] S. E. Roberts, L. A. Button, and J. G. Williams, "Prognosis following upper gastrointestinal bleeding," PLoS One, vol. 7, no. 12, Article ID e49507, 2012.

[5] J. R. Saltzman, L. L. Strate, V. Di Sena et al., "Prospective trial of endoscopic clips versus combination therapy in upper GI bleeding (PROTECCT-UGI bleeding)," The American Journal of Gastroenterology, vol. 100, no. 7, pp. 1503-1508, 2005.

[6] C. Hassan, L. Aabakken, A. Ebigbo et al., "Partnership with african countries: European society of gastrointestinal endoscopy (ESGE) - position statement," Endoscopy International Open, vol. 6, no. 10, p. E1247, 2018.

[7] K. Wellington and A. J. Wagstaff, "Tranexamic acid: a review of its use in the management of menorrhagia," Drugs, vol. 63, no. 13, pp. 1417-1433, 2003.
[8] M. Hoylaerts, H. R. Lijnen, and D. Collen, "Studies on the mechanism of the antifibrinolytic action of tranexamic acid," Biochimica et Biophysica Acta (BBA)-General Subjects, vol. 673, pp. 75-85, 1981.

[9] I. Roberts, D. Prieto-Merino, and D. Manno, "Mechanism of action of tranexamic acid in bleeding trauma patients: an exploratory analysis of data from the CRASH-2 trial," Critical Care, vol. 18, no. 6, p. 685, 2014.

[10] W. M. Bramer, M. L. Rethlefsen, J. Kleijnen, and O. H. Franco, "Optimal database combinations for literature searches in systematic reviews: a prospective exploratory study," Systematic Reviews, vol. 6, no. 1, p. 245, 2017.

[11] J. P. T. Higgins, D. G. Altman, P. C. Gotzsche et al., "The cochrane collaboration's tool for assessing risk of bias in randomised trials," BMJ, vol. 343, p. d5928, 2011.

[12] I. Roberts, H. Shakur-Still, A. Afolabi et al., "Effects of a highdose 24-h infusion of tranexamic acid on death and thromboembolic events in patients with acute gastrointestinal bleeding (HALT-IT): an international randomised, doubleblind, placebo-controlled trial," The Lancet, vol. 395, no. 10241, pp. 1927-1936, 2020.

[13] G. M. Hawkey, A. T. Cole, A. S. McIntyre, R. G. Long, and C. J. Hawkey, "Drug treatments in upper gastrointestinal bleeding: value of endoscopic findings as surrogate end points," Gut, vol. 49, no. 3, pp. 372-379, 2001.

[14] C. C. Von Holstein, S. B. Eriksson, and R. Kallen, "Tranexamic acid in gastric and duodenal bleeding," Scandinavian Journal of Gastroenterology, vol. 137, pp. 71-74, 1987.

[15] D. Bergqvist, S. Dahlgren, and Y. Hessman, "Local inhibition of the fibrinolytic system in patients with massive upper gastrointestinal hemorrhage," Upsala Journal of Medical Sciences, vol. 85, no. 2, pp. 173-178, 1980.

[16] A. Engqvist, O. Broström, F. v. Feilitzen et al., "Tranexamic acid in massive haemorrhage from the upper gastrointestinal tract: a double-blind study," Scandinavian Journal of Gastroenterology, vol. 14, no. 7, pp. 839-844, 1979.

[17] J. C. Biggs, T. B. Hugh, and A. J. Dodds, "Tranexamic acid and upper gastrointestinal haemorrhage-a double-blind trial," Gut, vol. 17, no. 9, pp. 729-734, 1976.

[18] F. Cormack, A. J. Jouhar, R. R. Chakrabarti, and G. R. Fearnley, "Tranexamic acid in upper gastrointestinal hæmorrhage," The Lancet, vol. 301, no. 7814, pp. 1207-1208, 1973.

[19] S. F. Bagnenko and V. G. Verbitskiǔ, "Antifibrinolitic therapy for the treatment of massive ulcerative gastro-intestinal bleedings," Khirurgiia, vol. 4, p. 42, 2011.

[20] C. D. Forbes, R. D. Barr, G. Reid et al., "Tranexamic acid in control of haemorrhage after dental extraction in haemophilia 
and Christmas disease," BMJ, vol. 2, no. 5809, pp. 311-313, 1972.

[21] L. Tengborn, M. Blombäck, and E. Berntorp, "Tranexamic acid-an old drug still going strong and making a revival," Thrombosis Research, vol. 135, no. 2, pp. 231-242, 2015.

[22] I. Roberts, "Tranexamic acid-a recipe for saving lives in traumatic bleeding," International Journal of Epidemiology, vol. 40, no. 5, p. 1145, 2011.

[23] T. Kobayashi and J. Sugiura, "The effect of a new potent antifibrinolytic agent, tranexamic acid," Journal of the Japanese Obstetrical \& Gynecological Society, vol. 13, no. 3, pp. 157-167, 1966.

[24] I. Roberts, H. Shakur, T. Coats et al., "The CRASH-2 trial: a randomised controlled trial and economic evaluation of the effects of tranexamic acid on death, vascular occlusive events and transfusion requirement in bleeding trauma patients," Health Technology Assessment (Winchester, England), vol. 17, no. 10, p. 1, 2013.

[25] M. Heidet, R. Amathieu, E. Audureau et al., "Efficacy and tolerance of early administration of tranexamic acid in patients with cirrhosis presenting with acute upper gastrointestinal bleeding: a study protocol for a multicentre, randomised, double-blind, placebo-controlled trial (the EXARHOSE study)," BMJ Open, vol. 8, no. 8, Article ID e021943, 2018.

[26] https://clinicaltrials.gov/ct2/show/NCT01713101. 